\title{
Intacs Intracorneal Ring Segments Complications in Patients Suffering from Keratoconus
}

\author{
Adel Barbara, Ramez Barbara
}

\section{ABSTRACT}

Intacs, intrastromal corneal rings are widely used to reduce myopia, astigmatism, keratometry readings and high order aberrations in patients suffering from keratoconus, almost 15 years have passed from the first procedure which was performed in the eye of a patient with unsatisfactory visual acuity and contact lenses intolerance.

Many publications including book chapters, retrospective studies, case reports and literatures reviews have been published on this issue.

In this review, we are reporting on the complications of Intacs implanted in keratoconic eyes, we are reporting on intraoperative and postoperative complications. The review although focusing on complications of the does not contradict the positive results of the procedure on the quality of life of the patients suffering from keratoconus and the its safety.

Keywords: Keratoconus, Intacs, Perforation, Keratitis, Extrusion, Astigmatism, Keratometry, High order aberrations, Intrastromal and corneal rings.

How to cite this article: Barbara A, Barbara R. Intacs Intracorneal Ring Segments Complications in Patients Suffering from Keratoconus. J Kerat Ect Cor Dis 2013;2(3):121-128.

Source of support: Nil

Conflict of interest: None declared

\section{INTRODUCTION}

There are four kinds of intracorneal ring segments (ICRS) available and various reports in the ophthalmic literature describe their effectiveness in treating keratoconus. The four types of ICRS are: (1) Intacs (Addition Technology Inc); (2) Intacs SK (Addition Technology Inc); (3) Ferrara Rings (Ferrara Ophthalmics) and (4) Kerarings (Mediphacos). The latter two have the same design and diameters, but are produced by different companies. In general, the ICRS differ in design, diameter, optical zone and length of arc, thus inducing different effects: the smaller the optical zone, the greater the effectiveness and the greater the ring segment diameter, the stronger is the effect obtained, and vice versa.

In this review, we shall discuss complications of Intacs intracorneal ring segments for treating keratoconus.

The concept of inserting polymethylmethacrylate segments (PMMA) as corneal inserts was first introduced by Fleming in $1987{ }^{1,2}$ The aim at that time was myopia correction. The design of the rings developed, from a single $360^{\circ}$ ring to two semicircular $150^{\circ}$ rings of hexagonal shape, with an inner diameter of $6.7 \mathrm{~mm}$, an external diameter of $8.1 \mathrm{~mm}$, and variable thicknesses, ranging from 0.25 to $0.45 \mathrm{~mm}$ with $0.05 \mathrm{~mm}$ (50 microns) increments. In the United States, 0.25 , $0.275,0.30,0.325$ and $0.35 \mathrm{~mm}$ segments are available for use; outside of the United States, 0.40 and $0.45 \mathrm{~mm}$-sized segments are also available. ${ }^{3}$ Intrastromal corneal ring segments Intacs were initially designed to correct low degree myopia, by flattening the central corneal curvature. ${ }^{4}$ Using the ICRS as a spacer between the corneal lamellae produces a shortening of the central arc length proportional to the ring thickness 5 the peripheral portion of the anterior corneal surface is flattened and the peripheral area adjacent to ring insertion is displaced forward. ${ }^{2,6}$ The Intacs were approved by the FDA for the correction of low myopia, between 1 and $3 \mathrm{D}$ in 1996. ${ }^{7}$ Intacs are used to correct myopia of up to 4.5 diopters with no more than one diopter of astigmatism, according to the company nomograms. However, their use for the correction of myopia proved very limited, while vision correction by excimer laser, either by photorefractive keratectomy (PRK) or by laser assisted keratomileusis (LASIK), gained wide acceptance and popularity, by ophthalmologists and the myopic community alike, due to its safety, predictability and efficacy. Intacs produce comparable results for the correction of myopia. ${ }^{8}$ and their clinical safety and efficacy have been shown to be comparable to those of other refractive procedures, such as PRK and LASIK. ${ }^{9}$ The mechanism of myopia correction by Intacs is very logical and thus appealing. The cornea can by flattened without removing tissue from its centre (as in myopia correction by excimer laser), tissue is added to the cornea, the center of the cornea remains untouched, the surgery is reversible, the cornea regains its former preoperative shape after the removal of Intacs, with refraction and visual acuity essentially returning to preoperative levels within 1 to 7 weeks..$^{10}$ Asbell et al reported on the easy and safe removal of Intacs, whereby eyes returned to preoperative refractive status within 3 months. ${ }^{11}$ The position of the Intacs in the cornea is adjustable, and the rings can be replaced by thinner or thicker rings as needed. Increasing the rings' thickness increases the flattening effect on the cornea and vice versa. Exchange procedures, in which ring segments are exchanged for larger or smaller sizes, were successful in improving uncorrected visual acuity UCVA. ${ }^{10}$

Intacs were used for the correction of myopia after LASIK and PRK with satisfactory, safe, stable and predictable results, like in 'virgin' myopic eyes. ${ }^{12}$ Intacs were used as 
an alternative to laser surgery in patients with forme fruste keratoconus or with extremely thin corneas whose refractive error was less than $3.00 \mathrm{D} .{ }^{13}$ Satisfactory results were reported on Intacs for the correction of myopia of less than 4.5 diopters in 39 eyes of 21 patients, in patients excluded from laser surgery because of abnormal topography and forme fruste keratoconus. In one patient, the Intacs were removed because of unsatisfactory results; in seven eyes, the rings were exchanged for thicker ones because of under correction. ${ }^{14}$

\section{Intacs and Keratoconus}

In 2004, Intacs received FDA approval under the humanitarian device exemption (HDE) process for the treatment of myopia and astigmatism in patients with keratoconus, when specific criteria are met. The HDE process, which is available for devices treating conditions that affect less than 4,000 Americans per year, does not require the manufacturer to provide data confirming the efficacy of the device, but rather data supporting its 'probable' benefit.

The first Intacs implantation for improving VA in a keratoconic patient was performed by Joseph Colin in 1997. ${ }^{15}$ Intacs were inserted in a contact lens intolerant patient with unsatisfactory visual acuity. As a result of the Intacs implantation the astigmatism and the corneal steepening were reduced. This patient completed a 10-year follow-up with stable results. Since then, many studies have been published in the literature confirming the positive results of Intacs implantation in keratoconic eyes.

\section{Indications for Corneal Rings in Keratoconus}

Indications for treating keratoconus by corneal ring insertion include the following:

1. Unsatisfactory VA with glasses

2. Contact lenses intolerance

3. Mild-to-moderate keratoconus

4. K reading $<58 \mathrm{D}$

5. Clear cornea and optical zone with no corneal scarring

6. Patients who desire modest improvements in their visual acuity.

7. Corneal thickness $>450 \mu \mathrm{m}$ in the area of the proposed tunnels, where Intacs are expected to be inserted.

Improvement was reported in uncorrected visual acuity (UCVA) and best spectacle corrected visual acuity (BSCVA) in addition to reduction in spherical equivalent and keratometry readings. Caution must be taken when comparing these outcomes, because different samples of keratoconus eyes were evaluated and additionally different nomograms were used for ICRS implantation. ${ }^{16,17}$

Rabinovitz in his review on Intacs for treating keratoconus states: Most studies to date show an average of 2 to $3 \mathrm{D}$ of flattening accompanied by 2 to 3 lines of gain in bestcorrected vision. However, the range is large and variable ranging from 2 lines of loss of BCVA to a gain in 8 BCVA, 70 to $80 \%$ of the patients treated in all the studies noted an improvement in the best-corrected and uncorrected vision, in addition to a decrease in higher order aberrations.

\section{Complications}

Although ICSR surgery has so far shown positive results, complications can occur, both intraoperatively and postoperatively.

\section{Intraoperative Complications}

Intraoperative complications during ICRS implantation are rare, Ibrahim et al reported zero intraoperative complications in 186 eyes. $^{18}$

El-Husseiny reports no intraoperative or postoperative complications in 20 eyes of 16 patients among them 3 eyes with post- lasik ectasia and one eye with pellucid marginal degeneration all tunnels were performed by femtosecond laser, the mean follow-up is 6 months. ${ }^{19}$

Nevertheless, the following intraoperative adverse events have been described in relation to the mechanical procedure for corneal channelization, but always as isolated and rare events: segment decentration, asymmetry of the implants, inadequate depth of channel, and superficial channel dissection with anterior Bowman's layer perforation. Other complications include mechanical epithelial defects at the keratotomy site, extension of the incision toward the central visual axis or toward the limbus, shallow placement and/or uneven placement of the Intacs segments, and posterior corneal perforation during channel creation. ${ }^{16,17}$ Intacs implantation was aborted in one eye of a patient who presented with successful Intacs implantation in the other eye because of intraoperative perforation. ${ }^{20}$

Preoperative sphere and cylinder proved to be statistically significant parameters associated with intra operative decentration, which can occur also with femtosecond assisted channel dissection in Intacs implantation. ${ }^{21}$ The mechanism of the decentration, as reported by Ertan et al is that during applanation for Intacs correction by a femtosecond laser, the cornea and pupil are not in their natural position, which leads to decentration and misalignment of the segments. ${ }^{22}$ Guel et al reported on acute corneal hydrops which was observed on the following day at surgery in a 14 years old patient suffering from advanced keratoconus, two ISCR were implanted, 'probable break in Descemet membrane occurred while implanting the Intac'. ${ }^{23}$ 


\section{Postoperative Complications}

Kanellopoulos et al report a $35 \%$ postoperative complication rate in 20 eyes operated. This is the highest postoperative complication rate reported. It included segment movement and exposure as well as corneal melting. There was one case of anterior chamber perforation; 6 eyes had ring exposure secondary to corneal thinning over the implants at 3 and 6 months follow-up, and a dense corneal infiltrate developed in one patient at 7 months postoperatively. ${ }^{24}$ Other postoperative complications reported include segment extrusion, corneal neovascularization, infectious keratitis, mild channel deposits around Intacs ring segment, segment migration, epithelial plug at the incision site, corneal haze around segments or at the incision site, corneal melting, night halos, chronic pain (only one case described, additional details follow) and (only one case of) focal edema around segments. ${ }^{17}$ Other rare complications include persistent inflammation, persistent fluctuation of vision, intraocular inflammation, photophobia, loss of uncorrected and bestcorrected visual acuity and vascularization of the wound. ${ }^{3}$

In the report by Ferrer et al on explantation of ICRS, there were more complications numerically in the Intacs group in those cases in which the channels were created by femtosecond than mechanically. ${ }^{25}$ This fact contradicts - at least in terms of postoperative complications - the claim that femtosecond assisted Intacs implantation is safer than the mechanical Intacs implantation procedure. Complaints of halo and glare that occur more frequently at night are not uncommon, because the procedure is frequently performed in younger patients with pupils of $7 \mathrm{~mm}$ (larger than the inner diameter of Intacs, which is $6.7 \mathrm{~mm}$ ). Alphagan drops may be tried in these cases. Unexplained loss of BSCVA 1 year after Intacs implantation necessitated a penetrating keratoplasty (PKP) in a case reported by Guel et al. ${ }^{26}$

Pannus may compromise the results of PKP by increasing the chance of rejection. Regression of deep pannus was reported by Cosar et al. ${ }^{27}$ They reported on a case of late deep corneal vascularization noted 3 years after intrastromal corneal ring segments (Intacs) implantation for the treatment of keratoconus, which necessitated the removal of the rings. The pannus subsided 10 days after rings removal and topical treatment with corticosteroids. Ibrahim et al. report on one case of corneal vascularization $(0.53 \%)$ which appeared 18 months post-Intacs implantation in a patient who used soft contact lenses. ${ }^{18}$ Lovisolo et al reported on Intacs removal due to neovascularization around the edge of one Intac and extrusion 1 year postoperatively. ${ }^{28}$ Topography guided PRK followed by collagen corneal cross-linking (CXL) was performed 6 months after the removal of Intacs. Six months after the novel PRK and CXL, the patient's UCVA was 20/25 and BCVA 20/20 and the blood vessels disappeared.

\section{Explantation and Extrusion}

The most frequent postoperative complication is extrusion, which leads to explantation of the segment implants. Explantation may be performed if the patient is dissatisfied with the visual postoperative outcomes.

Explantation rate varies significantly among studies, ranging from 0.98 to $30 \% .{ }^{16}$ Colin reported explantation in $12 \%$ of eyes implanted with Intacs, due to dissatisfaction with visual symptoms. ${ }^{29}$ ICRS can be safely and easily explanted, with visual, refractive and topographic features returning to near the pre-implantation levels. ${ }^{30}$ Ibrahim et al reported on two explanted rings (1.07\%), one due to direct ocular trauma 6 weeks post-surgery and the other due to continued progression of the cone 1 year postsurgery. Both Intacs were easily removed under topical anesthesia through the original incision. Both patients underwent a successful deep anterior lamellar keratoplasty 4 weeks postIntacs removal. No eyes lost any lines compared to their preoperative UCVA and BCVA. ${ }^{18}$

Ferrer et al reported on the main reasons for explantation of ICRS (which included Intacs and Ferrara Rings) over a period of 9 years (between 2000-2008) and the relationship with microscopic findings on the ICRS surface. ${ }^{25}$ Intrastromal corneal ring segments were explanted from 58 eyes (47 patients) of 250 implanted ICRS, a rate of $22.8 \%$. The main cause was extrusion $(48.2 \%$ of explanted segments); consequently, $10 \%$ of the ICRS implanted were removed due to extrusion, followed by unsatisfying refractive outcome $(37.9 \%)$, keratitis $(6.8 \% ; 3.7 \%$ culture positive), and corneal melting and perforation (6.8\%). The mean interval in all cases was 7.65 months (range 0.1 to 82.0 months). Thirty seven of the 58 eyes had Intacs: 18 Intacs were removed because of extrusion, 12 because of refractive failure. All cases of corneal melting were in eyes with Intacs ( 2 had tunnel creation by femtosecond laser and 1 by mechanical dissection) and in all cases, the clinician observed melting before extrusion and extracted the ICRS to prevent further melting. In four cases (3 of them Intacs), ICRS were removed because of suspected infection, in 2 cases $(3.4 \%)$ the cultures were positive (Staphylococcus aureus and Streptococcus mitis) and in two cases negative. It is likely that the longer implantation-to-explantation time (years) was caused by stromal thinning over time and that the shorter time was due to incorrect positioning. Kugler et al reported in an observational retrospective case series on four cases of corneal melting after insertion of ICRS for the treatment of ectasia. Each of the four cases of corneal melt occurred in an eye with a corneal incision overlying the ICRS, three of them in eyes after radial keratotomy (RK). ${ }^{31}$ The rate of ICRS explantation and its correlation 
to the surgical technique, type of segment, and year of implantation will be the focus of an upcoming study by the same authors. ${ }^{25}$ Colin reported on explanation of the ICRS from four (4\%) eyes without complications or sequela. ${ }^{32}$

\section{Evaluation of the Depth of Implanted Intacs}

Shallow implantation is one of the causes of extrusion. It has been associated with ring superficialization, stromal thinning, and epithelial breakdown. ${ }^{33-36}$ Lai et al performed optical coherence tomography (OCT) to examine the depth of Intacs implanted in the corneal stroma. OCT performed between 7 and 43 days after implantation demonstrated that the position of the distal portions of the ring segments was shallower than that of the portion closer to the insertion site $(p=0.003)$. They reported that segments placed in the inferior cornea $(p=0.008)$ experienced more distal shallowing. Shallower depth was associated with greater fractional anterior stromal compression $(p=0.04)$. The authors claimed that greater tensile strain on the anterior stroma could lead to gradual stromal breakdown in a process similar to keratoconus disease progression. In addition, these regions may experience more forward bowing of the anterior corneal surface over the implant. The greater anterior surface curvature may explain the epithelial breakdown. Superficially placed segments also may compromise diffusion of nutrients to the epithelium. ${ }^{37}$ Kamburgolu et al used Pentacam to assess the depth of Intacs implanted by femtosecond laser and reported decreased depth of Intacs at the end of the first postoperative year in all measured points, and the change was statistically significant at the superior, inferior, and temporal sides of the Intacs. The degree of change was not correlated with size of the Intacs, preoperative central corneal thickness, or mean keratometric values. ${ }^{38}$ Naftali et al in a retrospective comparative study compared the depth of ICRS with the expected depth value using OCT in 18 eyes with ICRS, some implanted with Intacs and some with Kerarings. No difference was found between the mean depths of the distal, central, and proximal point measurements. There was a significant difference between the expected ICRS depth and the OCT measurements (mean $480 \pm 20$ ) and $360 \pm 68$ ), respectively meaning shallower implantation than expected. No significant difference was found between the depth of Intacs and kerarings. ${ }^{39}$

A Visante OCT scan showed Intacs partially bulging into the anterior chamber and partially compressing the stroma above them, in a case with two Intacs segments: one implanted $0.25 \mathrm{~mm}$ superiorly and 0.45 inferiorly in a keratoconic eye. The thicker Intacs segment appeared to compress the overlying stroma. ${ }^{40}$ Toroquetti and Ferrara, in a letter of comment on the article of Ferrer on causes of ICRS explantation, wrote that there are 2 major causes of ICRS extrusion: superficial implantation of a segment and the placing of a segment too close to the incision. They claimed that as a general rule, the thickness of the implanted ICRS should not be more than $50 \%$ of the corneal thickness in the ring track. Moreover, the incision depth should preferentially be set at $80 \%$ of the corneal thickness. Deeply located ICRS produce better results and also leave a greater amount of corneal stroma between the ICRS and the corneal epithelium, which could theoretically protect from extrusion related to progressive stromal thinning. Only rarely does an extrusion begin in the middle of the segment or far from the incision. An ICRS that is placed close to the incision, especially if implanted superficially, is predisposed to adjacent corneal thinning and melting and subsequent extrusion. ${ }^{41}$

\section{Corneal Melting Post-Intacs}

DR Kugler reports from a literature review on corneal melting in 12 eyes out of 1,835 eyes that had undergone implantation related to keratoconus or ectasia. $0.7 \%$; seven of the cases (58\%) had an incision overlying the implant, five cases did not. The same author report on four cases of melting three because of ectasia after radial keratotomy and one in a case of pellucid marginal degeneration (PMD). ${ }^{42}$

\section{Migration of Intacs}

Park et al describe a case of a 53-year-old woman with keratoconus who presented with a dislocated Intacs in the anterior chamber 3 weeks after surgery. The Intacs were removed. ${ }^{43}$ In a unique report of corneal Intacs migration following implantion using the femtosecond laser, Feldman et al described a case where postoperatively, both rings migrated inferiorly and overlapped each other in a doublestacked formation. This migration led to a dramatic improvement in VA.

Recurrent ring segment migration toward the incision which was was treated by fixating it to the cornea with a 10-0 nylon suture through the channel has been reported, the suture was removed at 1 month postoperatively. ${ }^{44}$

\section{Keratitis Post-Intacs}

The incidence of infectious keratitis after Intacs implantation for the treatment of myopia is low, ranging from 0.2 to $0.63 \% .^{33,48}$ Keratitis was reported after Intacs inserted with either implantation technique. Proper management of this condition requires ICRS explantation and intensive topical antibiotics. Keratitis was reported in two of 134 eyes implanted with Intacs for treating keratoconus, one case of Intacs implanted mechanically and one femtosecond laser assisted implantation. ${ }^{45}$ Levy et al reported on keratitis 
in a case which developed weeks after femtosecond laser assisted implantation of Intacs, and they state that it was reported at least in one other case. ${ }^{46}$ However, based on the literature review, the number of cases is greater than two. ${ }^{25}$ Chaudhry et al reported on a 20 -year-old woman who developed bilateral severe infectious keratitis 11 days after uncomplicated implantation of ICRSs for keratoconus. Cultures obtained at the time of initial presentation yielded Streptococcus viridans. The patient responded well to the treatment and was left with stromal scars in both corneas. The authors concluded that early recognition of infection, aggressive treatment with antibiotics and, in some cases, removal of ICRSs may be necessary to prevent serious sight-threatening complications following this procedure. ${ }^{47}$ Infection most commonly occurs as a result of a loose stitch or as a result of wound gape from migration of the Intacs to the site of the wound. Culturing the Intacs might be helpful in isolating the organism. ${ }^{3}$ A rare report of fungal keratitis (C. parapsilosis) following Intacs insertion was reported by Mitchelli et al. Extrusion of the implants was noted 5 months post-insertion and replaced. Three months later, monocular infiltrates and an epithelial defect were observed. Medical treatment failed, bacteriological investigation was negative therapeutic keratoplasty was performed 10 months following initial placement of the ISCR. A histopathologic diagnosis of Candida parapsilosis keratitis was made and confirmed by polymerase chain reaction. ${ }^{48}$

\section{Traumatic Shattering of Intrastromal}

Traumatic shattering of intrastromal segments due to blunt trauma, with successful removal of the fragments has been reported. The authors reported that the eye was white, the cornea clear, three fractures lines were visible in the upper Intac and two in the lower one. They hypothesized that the shattered segments had sharp edges and there was a concern of anterior or posterior erosion of the fragments through the cornea, yet they report that they removed the segments also at the patient's insistence. ${ }^{49}$ Removing the segments due to the patient's insistence is beyond discussion, whereas the possible removal of the ring segments because of an unverified hypothesis that keeping the segments might cause anterior or posterior erosion merits a comment, given that there has been no report in the literature concerning this type injury to the Intacs, and furthermore, the $10 \%$ incidence of extrusion that has been reported was not associated with damaged edges of the segments. ${ }^{25}$

\section{Pain after Intacs}

Randleman reported chronic pain after Intacs implantation and persistent discomfort caused by direct contact between the segment and corneal nerve, which did not improve with topical medication or a bandage contact lens. After removal of the segments, the pain resolved. Confocal microscopy demonstrated a corneal nerve in direct contact with the inferior Intacs segment. One day after the removal, the patient reported complete resolution of pain, and she remained pain free. ${ }^{50}$

\section{Infiltrates in the Intacs Channels}

Rau et al reported a $13.3 \%$ prevalence of corneal infiltrates. ${ }^{51}$ Ruckhofer et al reported the frequency of intrastromal deposits after Intacs implantation in myopic eyes at 24 months: 213 (74\%) of 359 myopic eyes had deposits and the incidence of deposits increased with ring thickness and duration. ${ }^{52}$ However, these deposits do not appear to affect the performance of the segment rings or the progression of keratoconus. Reporting on the results of Intacs implantation using two different channel sizes created by femtosecond laser, Ertan et al found yellow-white deposits in 10 eyes $(10.30 \%)$ of the large channel group and in 29 eyes (46.77\%) of the narrow channel group. ${ }^{53}$ Guel reported on a case of sterile infiltration along one segment that required the extraction of one of the inserts. This infiltration was probably related to underlying rosacea that was diagnosed postoperatively. ${ }^{26}$ Ertan et al observed an epithelial plug at the incision site in $15.2 \%$ of eyes. This may have been the result of trauma during Intacs placement and a temporary gap at the unsutured incision site. Over 6 postoperative months, a few granulomatous particles around the Intacs segment were observed in $8.5 \%$ of the 118 eyes. $^{53}$

Microdeposits and abnormal lamellar structure adjacent to Intacs were seen using confocal microscopy. ${ }^{54}$ Deposits on or adjacent (both inward and outward) to the segments are most probably related to intracellular lipids accumulation or morphologically abnormal cellular structures. ${ }^{4,55}$ The incidence of intrastromal deposits (intracellular lipids) in the corneal tunnel can be as high as $60 \% .^{52}$ Twa et al studied morphological characteristics of lamellar channel deposits in the human eye next to an Intac implant, extracellular matrix (ECM) components typically associated with fibrosis were observed. The keratoconus cases displayed typical Bowman layer breaks and subepithelial fibrosis with deposition of various ECM components. In all cases, some keratocytes around Intacs were positive for specific proteinases associated with stromal remodelling. ${ }^{56}$ Another study showed that ring segments induced keratocyte apoptosis, but these changes are reversible after implant removal. ${ }^{52}$

Samimi et al reported on the histopathological findings of keratoconus buttons at the time of keratoplasty following Intacs implantation. ${ }^{57}$ This retrospective study involved 
eight patients who had PKP after removal of Intacs inserts, because of a poor refractive outcome or insert extrusion. Conventional histology showed hypoplasia of the epithelium immediately surrounding the channel. There was no evidence of an inflammatory response or foreign-body granuloma. Keratocyte density was decreased above and below the tunnel. All samples stained negatively with a smooth muscle actin, indicating that myofibroblasts were not present. These changes were no longer visible after PKP was performed, more than 6 months after Intacs explantation. The authors concluded that histological changes seemed to be entirely reversible after implant removal. ${ }^{57}$ Ly et al assessed the structure and location of intrastromal lipid deposits after implantation of Intacs, using in vivo confocal microscopy in seven eyes of six patients, examined 5 years or two months after uncomplicated implantation of Intacs for the correction of mild myopia. In the peripheral cornea of eyes examined 5 years after surgery, epithelial and endothelial cell layers appeared normal. Stromal haze was seen surrounding the implants in all eyes examined, but no keratocyte activation was noted. Reflective amorphous or crystalline structures consistent with lipid deposition were detected in all eyes with long-term implantation of Intacs. Deposits were localized to the inner and outer edges of Intacs segments and to the region anterior to the implant. Confocal microscopy did not show any deposits in the eye examined 2 months after surgery, although the region anterior to the implant appeared hazy and edematous. Areas central to the implant appeared normal in all eyes. ${ }^{58}$ Ruckhofer et al performed confocal real-time microscopy on a total of 21 eyes from 11 patients. Seventeen eyes from 10 patients who underwent uncomplicated ICRS surgery to correct myopia and were examined after surgery (average 8.6 months; range 2-15 months). Three patients had the ICRS implanted into only one eye, and those eyes were compared with the untreated fellow eyes. One eye of another patient was examined 1 and 6 months after ICRS removal. In the central cornea, the researchers found normal morphologic features at all layers. In peripheral sections, epithelial cells with highly reflective nuclei in the basal cell layer were observed in six of 17 eyes (35\%) implanted with ICRS. They found an intact corneal nerve plexus and undisturbed corneal endothelium immediately underneath the ICRS. Around the ICRS, moderate fibrosis was seen. In one eye, linear structures in bamboo-like orientation were detected after ICRS removal in the last keratocyte layer underneath the collapsed tunnel. Concluding that the central corneal zone appeared unchanged, the corneal stroma adjacent to the ICRS was observed, which displayed a slight but distinct activation of wound healing. Epithelial cells with highly reflective nuclei in this region may be an indicator of increased biologic stress caused by the device. ${ }^{59}$
Ferrer et al found no inflammatory material on the surface of any ICRS explanted for refractive failure (poor refractive outcome), showing the biocompatibility of PMMA in the area of ICRS implantation. They found macrophages and deposits only in cases of extrusion, but not in cases of ICRS removal due to refractive failure. The deposits, unlike in other reports, were in the inner curvature, along the ICRS, or near the extruded end; in addition, the deposits appeared more diffuse. In most cases (68.8\%) of extruded segments, they observed inflammatory infiltrate that was larger near the wound, although deposits were seen at the segment edge. This indicates that epithelial breakdown and close contact between the corneal stroma and the tear film play a role in triggering this reaction. ${ }^{25}$ Migration of macrophages to the wound site, localized edema, and activation of keratocytes to fibroblast and myofibroblast phenotypes would be consistent with normal tissue response to surgical trauma. The lipid drops that were found on the surface of extruded ICRS were reported to be a consequence of trauma that occurred during implantation surgery or corneal suturing. ${ }^{25}$ The process of lipid accumulation might have been the result of host rejection, or it might have occurred because the superficial part of the stroma thinned overtime causing the extrusion. Although the second option seems more plausible, additional studies are required to substantiate this claim. The authors concluded that lack of inflammatory reaction in cases of ICRS explanted for refractive failure confirms the biocompatibility of PMMA segments in the corneal stroma. ${ }^{25}$ Accumulation of foamy histiocytes along the lamellar channels was reported ${ }^{60}$ Torquetti and Ferrara believe that the inflammatory cells and cell debris found in cases of extrusion are the consequence - rather than the cause - of the extrusion. The progressive epithelial and stromal thinning can lead to segment exposure, which in turn can lead to a local inflammatory reaction, triggering corneal melting around the segment, with subsequent extrusion. ${ }^{41}$ Whitish deposits were documented in the 5 months after Intacs implantation in, 8 months postoperatively the patient underwent PKP, histological examination showed intrastromal foamy histiocytes around the channels. ${ }^{20}$ A patient developed intrachannel deposits in both eyes approximately 4 months after bilateral Intacs implantation, which had increased significantly at 3 -year follow-up. The intrachannel deposits and haze spontaneously improved, and 9 years following implantation few deposits and little haze remained. ${ }^{61}$

\section{CONCLUSION}

The complications of Intacs implanted in keratoconic eyes do very rarely, if at all compromise vision in the implanted 
eyes, most of these eyes which develop complications require the removal of the ISCR which reverse the obtained improvement in VA, other options may still be offered such as reimplantation of ISCR, PRK with and without CXL, anterior lamellar keratoplasty (ALK), deep anterior lamellar keratoplasty DALK or PKP. Most of the eyes implanted with Intacs were candidates to PKP so even if the Intacs fail to improve their VA and they will need (DALK) Big bubble-assisted DALK procedure was performed at the time of Intacs removal in two eyes with unsatisfactory visual outcome; no intra- or postoperative complications occurred or PKP. ${ }^{62}$ The only complication which may compromise the results of DALK or PKP is pannus and pannus usually regresses after the removal of Intacs. Intacs remain a safe and reversible procedure it improves in the magority of operated eyes the UCVA, BCVA reduces the astigmatism and the keratometry and regularize the cornea, ISCR should be offered to nonscared corneas before keratoplasty.

\section{REFERENCES}

1. Fleming RLSD. The intra-stromal corneal ring: two cases in rabbits. J Refract Sug 1987;(3):227-232.

2. Fleming JF, Lee Wan WSD. The theory of corneal curvature change with the intra-stromal corneal ring. CLAO J 1989;15: 146-150.

3. Rabinowitz YS. Intacs for keratoconus. Int Ophthalmol Clin 2010;50(3):63-67.

4. Schanzlin DJ, Asbell PA, Burris TE, Durrie DS, et al. The intrastromal corneal ring segments. Phase II results for the correction of myopia. Ophthalmology 1997;104(7):1067.

5. Silvestrini T, Mathis M, Loomas BBT. A geometric model to predict the change in corneal curvature from the intrastromal corneal ring ICR. Invest Ophthalmol Vis Sci 1994;35:2023.

6. Patel S, Marshall JFFI. Model for deriving the optical performance of the myopic eye corrected with an intracorneal ring. J Refract Surg 1995;(11):248-252.

7. DJ S. Studies of intrastromal corneal ring segments for the correction of low to moderate myopic refractive errors. Trans Am Ophthalmol Soc 1997;97:815-890.

8. Schanzlin DJ, Abbott RL, Asbell PA, Assil KK, Burris TE, Durrie DS, et al. Two-year outcomes of intrastromal corneal ring segments for the correction of myopia. Ophthamology 2001;108:1688-1694.

9. Suiter BG, Twa MD, Ruckhofer JSD. A comparison of visual acuity, predictability, and visual function outcomes after intracorneal ring segments and laser in situ keratomileusis. Trans Am Ophthalmol Soc 2000;98:51-55.

10. Chan SMKH. Reversibility and exchangeability of intrastromal corneal ring segments. J Cataract Refract Surg 2002;28:676-681.

11. Asbell PA, Uçakhan ÖÖ, Abbott RL, et al. Intrastromal corneal ring segments: reversibility of refractive effect. J Refract Surg 2001;15-27.

12. Barbara A, Shehadeh-Masha'our RGH. Intacs after laser in situ keratomileusis and photorefractive keratectomy. J Cataract Refract Surg 2004;30(9):1892-1895.

13. Ys R. Intacs for keratoconus. Ophthalmol Clin 2006;46(3): 91-103.
14. Güell JL, Morral M, Salinas C, Elies D, Gris OMF. Intrastromal corneal ring segments to correct low myopia in eyes with irregular or abnormal topography including forme fruste keratoconus: 4-year follow-up. J Cataract Refract Surg 2010;36(7):1149-1155.

15. Colin J, Cochener B, Savary G, Malet F. Correcting keratoconus with intracorneal rings. J Cataract Refract Surg. Elsevier 2000;26(8):1117-1122.

16. Ertan A, Colin J. Intracorneal rings for keratoconus and keratectasia. J Cataract Refract Surg. Elsevier; 2007;33(7):13031314.

17. Piñero DP, Alio JL. Intracorneal ring segments in ectatic corneal disease - a review. Clinical and experimental ophthalmology. Wiley Online Library 2010;38(2):154-167.

18. TA I. After 5 years follow-up: do Intacs help in keratoconus? J Cataract Refract Surg 2006;(1):45-48.

19. El-Husseiny M, Tsintarakis T, Eppig T, Langenbucher ASB. Intacs intracorneal rings in keratoconus. Ophthalmol 2013;110(9):823-826.

20. Mohammad Al-Amry HMA. Insertion, histopathologic findings in two cases with history of intrastromal corneal segments. Middle East Afr J Ophthalmol 2011;18(4):317-319.

21. Ertan AKH. Factors influencing flap and Intacs decentration after femtosecond laser application in normal and keratoconic eyes. J Refract Surg 2008;24(8):797-801.

22. Ertan A KG. Analysis of centration of Intacs segments implanted with a femtosecond laser. J Cataract Refract Surg 2007;33(3):484-487.

23. Güell JL, Verdaguer P, Elies D, Gris OMF. Acute corneal hydrops after intrastromal corneal ring segment implantation for keratoconus. J Refract Surg 2012;38(12):2192-2195.

24. Kanellopoulos AJ, Lawrence HP, Perry HD, Donnenfeld ED. Modified intracorneal ring segment implantations (INTACS) for the management of moderate to advanced keratoconus: efficacy and complications. Cornea LWW 2006;25(1):29-33.

25. Ferrer C. Alio IJMA, et al. Causes of intrastromal corneal ring segment explantation: clinicopathologic correlation analysis. J Cataract Refract Surg 2010;36(6):970-977.

26. Güell JL, Morral M, Salinas C, Elies D, Gris OMF. Four-year follow-up of intrastromal corneal ring segments in patients with keratoconus. J Emmetropia 2010;1:9-15.

27. Cosar CB, Sridhar MSSB. Late onset of deep corneal vascularization: a rare complication of intrastromal corneal ring segments for keratoconus. Eur J Ophthalmol 2009;19(2):298-300.

28. Lovisolo CF, Mularoni AMF. Combining Intacs implantation with other refractive and non-refractive procedures. J Emmetropia 2010;1(3).

29. Colin J. European clinical evaluation: use of Intacs for the treatment of keratoconus. J Cataract and Refract Surg. Elsevier 2006;32(5):747-755.

30. Alió JL, Artola A R-MJ, et al. Changes in keratoconic corneas after intracorneal ring segment explantation and reimplantation. Ophthalmology 2004;111:747-751.

31. Kugler LJ, Hill S, Sztipanovits D, Boerman H, Swartz TS WM. Corneal melt of incisions overlying corneal ring segments: case series and literature review. Cornea 2011;30(9):968-971.

32. Colin JMF. Intacs for the correction of keratoconus: two-year follow-up. J Cataract Refract Surgery 2007;33: 69-75.

33. Apuano CJ, Sugar A, Koch DD, et al. Intrastromal corneal ring segments for low myopia; a report by the American Academy of Ophthalmology. Ophthalmology 2001;108:1922-1928. 
34. Ruckhofer J, Stoiber J, Alzner E GG. One year results of European multicenter study of intrastromal corneal ring segments. Part 2: complications, visual symptoms, and patient satisfaction; the Multicenter European Corneal Correction Assessment Group Study. J Cataract Refract Surg 2001;27: 287-296.

35. McDonald JEDD. Removal of Intacs with a fractured positioning hole. [letter]. J Refract Surg 2004;20:182-183.

36. Hofling-Lima AL, Branco BC, Romano AC, Campos MQS, Moreira H, Miranda D, et al. Corneal infections after implantation of intracorneal ring segments. Cornea LWW 2004;23(6):547-549.

37. Lai MM, Tang M, Andrade EMM, Li Y, Khurana RN, Song JC, et al. Optical coherence tomography to assess intrastromal corneal ring segment depth in keratoconic eyes. J Cataract Refract Surg. Elsevier 2006;32(11):1860-1865.

38. Kamburoglu G, Ertan A, Saraçbasi O. Measurement of depth of Intacs implanted via femtosecond laser using Pentacam. J Refract Surg 2009;25(4):377-382.

39. Naftali M, Jabaly-Habib H. Depth of intrastromal corneal ring segments by OCT. European journal of ophthalmology [Internet]. 2012 Oct 30 [cited 2012 Dec 2];00:1-6. Available at: http://www.ncbi.nlm.nih.gov/pubmed/23112039

40. Kaiserman I, Bahar IRD. Optical coherence tomography provides insight into the effect of intacs in keratoconus. Arc Ophthalmol 2008;126(4):571-572.

41. Torquetti LFP. Reasons for intrastromal corneal ring segment explantation. J Cataract Refract Surg 2010;36(11):2014.

42. No Title. ophthalmology times. 2010. Available at: (http://ophthalmologytimes.modernmedicine.com/ ophthalmologytimes/news/modernmedicine/modern-medicinenews/risk-cornea-melt-reviewed)

43. Park S, Ramamurthi SRK. Late dislocation of intrastromal corneal ring segment into the anterior chamber. J Cataract Refract Surg 2010;10:2003-2005.

44. Jarade E, Dirani A, Fadlallah A, Antonios R CG. New technique of intracorneal ring segments suturing after migration. J Refract Surg 2013;29(10):722-724.

45. Mulet ME, Pérez-Santonja JJ, Ferrer CAJ. Microbial keratitis after intrastromal corneal ring segment implantation. J Refract Surg 2010;26(5):364-369.

46. Levy JLT. Keratitis after implantation of intrastromal corneal ring segments (Intacs) aided by femtosecond laser for keratoconus correction: case report and description of the literature. Euro J Ophthalmol 2010;20(4):780-784.

47. Chaudhry IA, Al-Ghamdi AAKO, et al. Bilteral infectious keratitis after implantation of intrastromal corneal ring segments. Cornea 2010;29(3):339-341.

48. Mitchell BM, Kanellopoulos AJFR. Post-intrastromal corneal ring segments insertion complicated by Candida parapsilosis keratitis. Clinical Ophthalmology Auckland, NZ 2013;7: 443-448.

49. Liu AME. Traumatic shattering of intrastromal corneal ring segments. J Cataract Refract Surg 2010;36(6): 1042-1044.
50. Randleman JB, Dawson DG. Larson PM, Russell BEH. Chronic pain after Intacs implantation. J Cataract Refract Surg 2006;36(5):875-878.

51. Rau MDD. Intrastromal corneal ring implantation for the correction of myopia: 12-month follow-up. J Cataract Refract Surg 2003;29:322-328.

52. Ruckhofer J, Twa MDSD. Clinical characteristics of lamellar channel deposits after implantation of Intacs. J Cataract Refract Surg 2000;26:1473-1479.

53. Ertan A, Kamburogulo GAU. Comparison of outcomes of 2 chanel sizes for intrastromal ring segment implantation with femtosecond laser in eyes with keratoconus. J Cataract Refract Surg 2007;33:648-653.

54. Kymionis GD, Grentzelos MA, Diakonis VF, Pallikaris AIPI. Nine-year follow-up of Intacs implantation for keratoconus. Open Ophthalmol J 2009;8(3):77-81.

55. Twa MD, Ruckhofer J, Kash RL, Costello MSD. Histological evaluation of corneal stroma in rabbits after intrastromal corneal ring implantation. Cornea 2003;22:146-152.

56. Twa MD, Kash RL, Costello MSD. Morphological characteristics of lamellar channel deposits in the human eye: a case report. Cornea 2004;23:412-420.

57. Samimi S, Leger F, Touboul DCJ. Histopathological findings after intracorneal ring segment implantation in keratoconic human corneas. J Cataract Refract Surg 2007;33:247-253.

58. Ly LT, McCulley JP, Verity SM, Cavanagh HD, Bowman RW PW. Evaluation of intrastromal lipid deposits after intacs implantation using in vivo confocal microscopy. Eye Contact Lens 2006;32(4):211-215.

59. Ruckhofer J, Böhnke M, Alzner E GG. Confocal microscopy after implantation of intrastromal corneal ring segments. Ophthalmology 2000;107:2144-2151.

60. Alkatan MAA, HM. Histopathologic findings in two cases with history of intrastromal corneal ring segments insertion. Middle East Afr J Ophthalmol 2011;18(4):317-319.

61. Kaufman MBDD. Spontaneous improvement of channel deposits following Intacs implantation. J Refract Surg 2011;27(4): 303-305.

62. Titiyal JS, Chawla BSN. Deep anterior lamellar keratoplasty with Intacs explantation in keratoconus. Eur J Ophthalmol 2010;20(5):874-878 .

\section{ABOUT THE AUTHORS}

\section{Adel Barbara}

Medical Director, Department of Ophthalmology, Hadassah Optimal Refractive Surgery Centre of Hadassah Hospital, Haifa, Israel; President of the Refractive Surgery Society, Haifa, Israel

Correspondence Address: Hadassah Optimal, 157 Yaffo Street Haifa, Israel, Phone: +972528500061, Fax: +97248516999, e-mail: adelbarbara@yahoo.com

\section{Ramez Barbara}

Specialist, Department of Ophthalmology, Hadassah Optimal, Haifa Israel 